\title{
Erratum to: Tensor products, asymptotic intertwinings and property $(R)$
}

\section{B.P. Duggal}

Published online: 12 October 2011

C) Springer-Verlag 2011

\section{Erratum to: Rend. Circ. Mat. Palermo \\ DOI 10.1007/s12215-011-0074-y}

The author apologizes for omitting a hypothesis from Lemma 3.4. The corrected statement of the lemma should read:

Lemma 3.4 If $A$ and $B$ are isoloid operators (i.e., the isolated points of their spectra are eigenvalues), then $\pi_{00}(A \otimes B) \subseteq \pi_{00}(A) \pi_{00}(B)$.

Proof Argue as in [1, Proposition 4], where the Hilbert space case is considered.

This effects Theorem 3.8, which should read:

Theorem 3.8 If $A \in B(\mathcal{X})$ and $B \in B(\mathcal{Y})$ are isoloid operators which satisfy property $(R)$, then $A \otimes B$ satisfies property $(R)$.

Proof Same as Theorem 3.8.

Consequently: Property $(R)$ transfers from isoloid operators to their tensor product.

The author thanks Prof. Carlos Kubrusly for pointing out this error.

\section{References}

1. Kubrusly, C.S., Duggal, B.P.: On Weyl and Browder spectra of tensor products. Glasg. Math. J. 50, 289302 (2008)

The online version of the original article can be found under doi:10.1007/s12215-011-0074-y.

B.P. Duggal $(\bowtie)$

8 Redwood Grove, Northfield Avenue, London W5 4SZ, UK

e-mail: bpduggal@yahoo.co.uk 